\title{
PERANCANGAN ARSITEKTUR SISTEM DAN TEKNOLOGI INFORMASI MENGGUNAKAN TOGAF ADM (STUDI KASUS DINAS PERHUBUNGAN KOTA BALIKPAPAN)
}

\author{
Soleh Ardiansyah ${ }^{1}$, Adani Setiorini ${ }^{2}$, Lovinta Happy Atrinawati ${ }^{3}$, Tegar Palyus Fiqar ${ }^{4}$ \\ 1,2,3,4 Program Studi Sistem Informasi - Institut Teknologi Kalimantan \\ Jl. Soekarno-Hatta Km.15, Karang Joang, Balikpapan, Kalimantan Timur 76127 \\ Email: lovinta@lecturer.itk.ac.id
}

\begin{abstract}
ABSTRAK
Pemanfaatan sistem atau teknologi informasi pada suatu organisasi diperlukan untuk meningkatkan efisiensi organisasi. Hal ini berkaitan dengan lajunya perkembangan sistem atau teknologi informasi yang berpengaruh pada proses bisnis yang sedang berjalan. Efektifitas tersebut berupa penyelarasan strategi bisnis dengan strategi sistem informasi dan melakukan transformasi bisnis. Namun, dilema yang dihadapi khususnya pada instansi Pemerintahan seperti Dinas Perhubungan Kota Balikpapan adalah bagaimana menyelaraskan antara strategi bisnis yang dimiliki dan strategi sistem informasi yang akan digunakan sehingga dapat mencapai tujuan organisasi. Menanggapi masalah tersebut, perlu dilakukan penyelarasan antara kebutuhan bisnis organisasi dan kebutuhan aplikasi untuk mendukung visi dan misi yang ingin dicapai oleh Dinas Perhubungan Kota Balikpapan. Hal ini dapat dicapai menggunakan kerangka kerja The Open Group Architecture Framework (TOGAF) yang memberikan metode secara detail mengenai bagaimana membangun, mengelola, dan menerapkan enterprise architecture yang dikenal dengan Architecture Development Method (ADM) yang selanjutnya biasa disebut TOGAF ADM. Penelitian ini menghasilkan pemetaan kebutuhan bisnis dan kebutuhan aplikasi untuk mendukung visi dan misi yang ingin dicapai melalui rancangan arsitektur SI/TI meliputi pemodelan arsitektur bisnis, arsitektur sistem informasi, dan arsitektur teknologi pada Dinas Perhubungan Kota Balikpapan.
\end{abstract}

Kata Kunci: Arsitektur Bisnis, Arsitektur Sistem Informasi, Arsitektur Teknologi, Dinas Perhubungan, TOGAF

\begin{abstract}
Utilization of information systems or technology in an organization is needed to improve organizational efficiency. This relates to the rapid development of information systems or technology that affect the ongoing business processes. The effectiveness is in the form of aligning business strategy with information system strategy and business transformation. However, the dilemma faced especially in Government agencies such as the Balikpapan City Department of Transportation is how to align business strategies and information systems strategies that will be used so as to achieve organizational goals. Responding to the problem, it is necessary to align between the business needs of the organization and the needs of the application to support the vision and mission to be achieved by the Balikpapan City Department of Transportation. This can be achieved by using the framework of The Open Group Architecture Framework (TOGAF) which provides a detailed method of how to build, manage and implement an enterprise architecture known as the Architecture Development Method (ADM), hereafter referred to as TOGAF ADM. This research produces a mapping of business needs and application needs to support the vision and mission to be achieved through the information systems or technology architecture design including business architecture modeling, information system architecture, and technology architecture on the Balikpapan City Department of Transportation.
\end{abstract}

Keywords: Business Architecture, Department of Transportation, Information System Architecture, Technology Architecture, TOGAF

Author Korespondensi (Lovinta Happy Atrinawati)

Email: lovinta@lecturer.itk.ac.id 


\section{PENDAHULUAN}

Pemanfaatan sistem atau teknologi informasi pada suatu organisasi mulai dikembangkan dengan strategi yang beragam, hal ini diperlukan terlebih pada instansi Pemerintahan karena lajunya perkembangan sistem atau teknologi informasi akan berpengaruh pada proses bisnis yang sedang berjalan. Pada praktiknya, tidak sedikit pengembangan sistem atau teknologi informasi mengalami kegagalan, hal ini hampir dipastikan karena adanya ketidaksesuaian terhadap kebutuhan serta tujuan organisasi [1]. Untuk mengakomodasi masalah yang terjadi dalam suatu organisasi dengan memanfaatkan inovasi teknologi untuk memenuhi harapan arsitektur sistem informasi yang dinamis dan terus berkembang, dibutuhkan kerangka kerja yang nantinya dapat membantu menyelaraskan kebutuhan bisnis organisasi dan kebutuhan aplikasi untuk mendukung visi dan misi yang ingin dicapai [2]. Pendekatan ini dikenal sebagai Enterprise Architecture atau biasa disebut Arsitektur Sistem Informasi dan Teknologi Informasi (Arsitektur SI/TI).

Arsitektur SI/TI secara khusus pada saat melakukan investasi TI akan berguna untuk menginformasikan, memandu, dan membatasi keputusan bagi organisasi [3][4]. Selain itu, perlunya dilakukan perancangan arsitektur SI/TI agar organisasi atau perusahaan memiliki arsitektur informasi yang baku yang selanjutnya dapat digunakan sebagai landasan untuk pengembangan sistem informasi [5]. Arsitektur SI/TI menghasilkan blueprint atau deskripsi yang mendetil mengenai suatu rencana bagi organisasi yang menggunakannya. Sehingga organisasi dapat mengimplementasikan fungsi dalam menyelaraskan teknologi dengan proses bisnis organisasi atau perusahaan dan membuat nilai bisnis yang dihasilkan lebih optimal [6]. Salah satu penelitian menyatakan bahwa hasil arsitektur SI/TI ini dapat menjadi acuan perencanaan dan pengimplementasian rencana strategis TIK jangka menengah di pemerintahan [7]. Selain itu menurut penelitian lain, desain arsitektur SI/TI dapat dilakukan untuk menyelesaikan masalah yang tidak ada dasar arsitekturnya dan dapat menghasilkan blueprint sebagai bahan untuk rencana pengembangan TI sebagai panduan dalam menjalankannya pengembangan TI [8].
Pada instansi Pemerintahan yang ada di Indonesia, khususnya Kota Balikpapan salah satunya adalah Dinas Perhubungan Kota Balikpapan sangat mendukung penerapan sistem atau teknologi informasi dalam menjalankan tugas dan fungsi bisnisnya. Beberapa hal penting yang mendorong diperlukannya sistem atau teknologi informasi seperti pengambilan keputusan yang tidak didasari informasi yang tepat, ketersediaan informasi yang tidak relevan, kurangnya pemanfaatan informasi yang ada, informasi yang tidak tepat waktu dan tidak akurat, banyaknya terjadi duplikasi data, dan adanya data yang tidak dimanfaatkan dengan baik [9]. Selain itu, penerapan sistem atau teknologi informasi ini tidak hanya berperan menjadi perangkat penyokong kegiatan organisasi tetapi sudah menjadi suatu strategi dalam meningkatkan efektifitas untuk mencapai tujuan organisasi. Efektifitas tersebut berupa penyelarasan strategi bisnis dengan strategi sistem informasi dan melakukan transformasi bisnis [10].

Namun, dilema yang dihadapi oleh Dinas Perhubungan Kota Balikpapan adalah bagaimana menyelaraskan antara strategi bisnis yang dimiliki dan strategi sistem informasi yang akan digunakan sehingga dapat mencapai tujuan organisasi. Keselarasan tersebut hanya didapatkan apabila organisasi dapat dengan baik mendefinisikan kebutuhannya. Perancangan terhadap kebutuhan sistem atau informasi yang baik harus dilihat dari berbagai sudut pandang pengembangan seperti pendefinisian arsitektur bisnis organisasi, arsitektur data yang digunakan, arsitektur aplikasi yang dibangun serta arsitektur teknologi yang mendukung jalannya sistem tersebut. Berdasarkan permasalahan yang telah disebutkan, untuk menciptakan keselarasan penerapan sistem informasi dengan kebutuhan organisasi dibutuhkan sebuah paradigma yang biasa disebut dengan arsitektur SI/TI.

Arsitektur SI/TI dibutuhkan guna meningkatkan efektifitas untuk mencapai tujuan organisasi melalui pemanfaatan SI/TI. Hal ini menjadikan arsitektur SI/TI memiliki peran penting dalam menyelaraskan serta mengintegrasikan proses bisnis yang dilakukan oleh Dinas Perhubungan Kota Balikpapan. Untuk memodelkan arsitektur SI/TI pada Dinas Perhubungan Kota Balikpapan, penulis memilih untuk menggunakan kerangka kerja The Open 
Group Architecture Framework (TOGAF) untuk menyelesaikan permasalahan ini. Konsep perancangan arsitektur SI/TI menggunakan kerangka kerja TOGAF memberikan metode secara detail mengenai bagaimana membangun, mengelola, dan menerapkan enterprise architecture yang dikenal dengan Architecture Development Method (ADM) atau selanjutnya biasa disebut TOGAF ADM [11].

Penggunaan pendekatan TOGAF ADM dipilih berdasarkan penelitian sebelumnya terkait arsitektur SI/TI. Dalam penelitian pertama, ditetapkan bahwa dengan TOGAF ADM, para peneliti dapat mengintegrasikan kebutuhan yang diperlukan terkait sistem informasi atau teknologi informasi yang sesuai dengan visi dan misi organisasi [12]. Penelitian lainnya dilakukan pada salah satu sekolah tinggi disampaikan bahwa peneliti dapat menghasilkan rancangan model arsitektur sistem informasi atau teknologi informasi yang sesuai dengan visi dan misi organisasi, serta perencanaan model arsitektur sistem informasi dapat menghasilkan proses perbaikan terhadap kinerja layanan sistem informasi secara menyeluruh dengan menggunakan TOGAF ADM [13]. Hal paling penting berdasarkan penelitian yang dilakukan sebelumnya menyatakan bahwa sebesar 92\% kompleksitas dari metodologi TOGAF ADM dapat mendukung arsitektur SI/TI dibandingkan dengan metodologi lainnya, selain itu input dan ouput kerangka kerja TOGAF dinyatakan lebih baik dari metodologi lain [14]. Oleh karena itu, untuk merancang arsitektur SI/TI pada Dinas Perhubungan Kota Balikpapan penulis memilih untuk menggunakan kerangka kerja TOGAF ADM.

\section{METODOLOGI}

Pendekatan metodologi perancangan arsitektur SI/TI yang digunakan pada Dinas Perhubungan Kota Balikpapan menggunakan siklus TOGAF ADM khususnya pada tahap A sampai tahap E yang dapat dilihat pada Gambar 1 berikut:

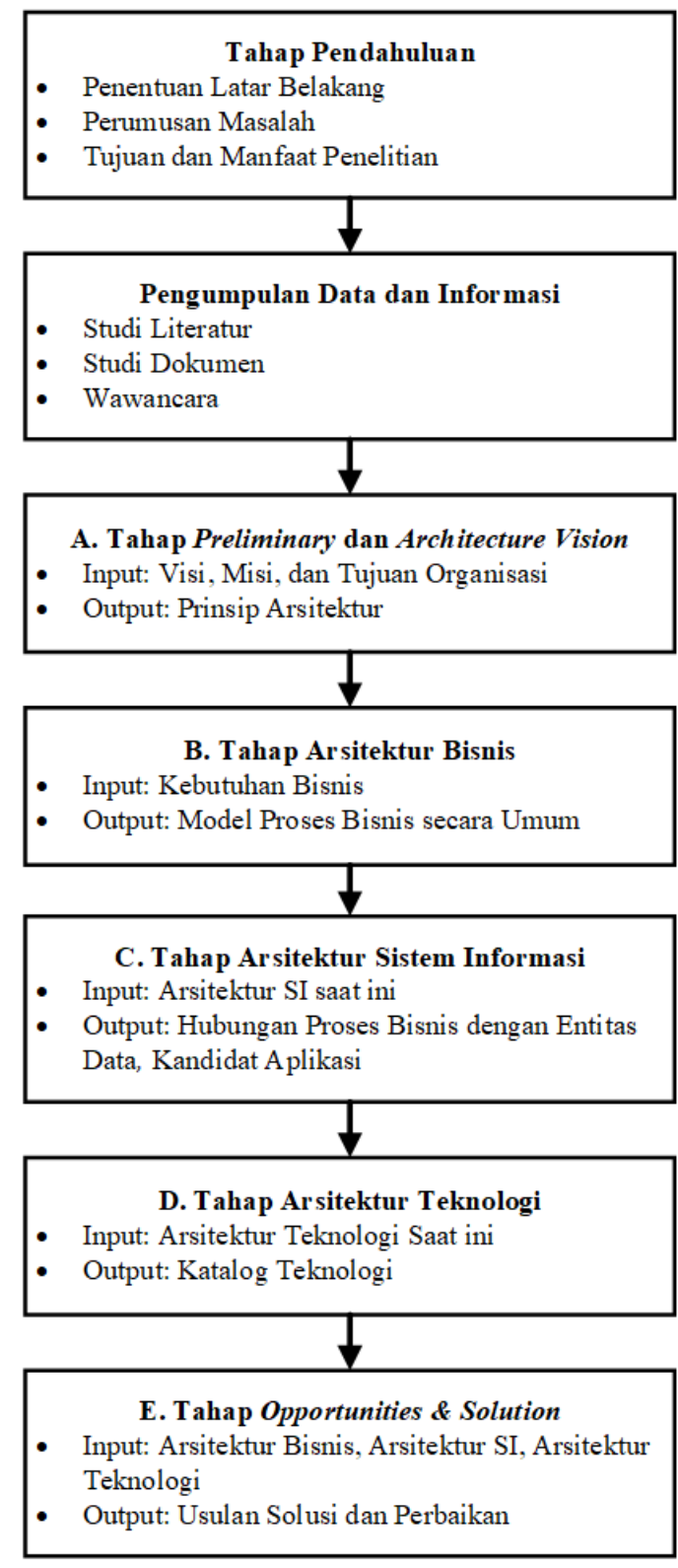

Gambar 1. Tahapan Metodologi Penelitian

\section{Pendahuluan}

Penentuan latar belakang dilakukan untuk mendapatkan rumusan masalah, tujuan dan manfaat penelitian, sehingga didapatkan penjelasan yang lebih detail mengenai penelitian.

\section{Pengumpulan Data dan Informasi}

Pengumpulan data melalui studi literatur, studi dokumen, dan wawancara dilakukan untuk mendukung proses penelitian sehingga sesuai dengan kondisi terkini.

\section{Tahap A: Preliminary dan Architecture Vision}


Pada tahap ini dilakukan identifikasi tujuan bisnis dan teknologi dari Dinas Perhubungan Kota Balikpapan dan prinsip dasar yang digunakan dalam pengembangan arsitektur SI/TI yang sesuai dengan kebutuhan Dinas Perhubungan Kota Balikpapan.

\section{Tahap B: Arsitektur Bisnis}

Dilakukan analisis proses bisnis yang ada sehingga dapat digunakan sebagai bahan rancangan dalam membuat sistem baru. Langkah-langkah yang dilakukan dengan memodelkan proses yang ada pada Dinas Perhubungan Kota Balikpapan.

\section{Tahap C: Arsitektur Sistem Informasi \\ a. Arsitektur Data}

Dilakukan identifikasi data utama (entitas data) berdasarkan arsitektur bisnis untuk mendefinisikan entitas data yang relevan dengan proses bisnis yang ada pada Dinas Perhubungan Kota Balikpapan.

\section{b. Arsitektur Aplikasi}

Didefinisikan jenis-jenis sistem informasi yang diperlukan dalam memproses data dan mendukung kebutuhan bisnis.

\section{Tahap D: Arsitektur Teknologi}

Mendefinisikan pembangunan arsitektur teknologi yang diinginkan, dimulai dari penentuan jenis kandidat teknologi yang diperlukan dengan menggunakan katalog teknologi yang meliputi perangkat lunak, perangkat keras, dan jaringan.

\section{Tahap E: Opportunities \& Solution}

Beberapa tahapan yang diuraikan yaitu, mengidentifikasi hubungan aplikasi dengan fungsi bisnis, membuat ruang lingkup solusi sistem informasi, melakukan penyusunan prioritas pengembangan sistem informasi.

\section{HASIL DAN PEMBAHASAN}

Metodologi yang digunakan pada penelitian untuk mengembangkan dan mengimplementasi-kan perancangan arsitektur sistem informasi dan teknologi yakni metode TOGAF ADM dengan tahapan sebagai berikut:

\section{Preliminary dan Architecture Vision}

Visi Dinas Perhubungan Kota Balikpapan adalah "Terwujudnya transportasi yang handal di Kota Balikpapan". Visi tersebut mengandung pengertian bahwa pelayanan yang diberikan
Dinas Perhubungan kepada stakeholdernya yaitu perusahaan jasa angkutan dan masyarakat pada umumnya harus memenuhi keinginan dan tuntutan berupa pelayanan pengaturan pelayanan transportasi yang lancar, cepat dan nyaman.

Misi Dinas Perhubungan Kota Balikpapan antara lain sebagai berikut:

a. Meningkatkan kualitas SDM aparat dan pemakai jasa transportasi,

b. Mengembangkan manajemen dan rekayasa transportasi,

c. Mendorong tersedianya kendaraan yang ramah lingkungan, dan

d. Menciptakan pemerataan pelayanan angkutan umum.

Dinas Perhubungan Kota Balikpapan memiliki tujuan organisasi, yaitu:

a. Meningkatkan keselamatan dan kelancaran transportasi,

b. Meningkatkan pengembangan sarana dan prasarana transportasi, dan

c. Mempertahankan dan meningkatkan jasa pelayanan sarana dan prasarana transportasi sesuai standar pelayanan.

Prinsip-prinsip dalam merancang arsitektur

SI yang ada di Dinas Perhubungan Kota

Balikpapan adalah sebagai berikut:

a. Prinsip bisnis: memaksimalkan manfaat bagi perusahaan atau organisasi, keberlangsungan bisnis, aplikasi yang umum digunakan, berorientasi layanan, ketaatan terhadap hukum.

b. Prinsip data: data adalah aset, data dapat dibagi bersama, data mudah diakses, keamanan data, mudah untuk digunakan, kemandirian teknologi.

c. Prinsip teknologi: mengontrol keragaman teknologi, perubahan berdasarkan kebutuhan-kebutuhan untuk pembaruan, interoperabilitas.

\section{Arsitektur Bisnis}

Secara umum, terdapat 4 (empat) proses bisnis yang dilakukan di Dinas Perhubungan Kota Balikpapan, yaitu:

a. Penyusunan, merupakan kegiatan penyusunan kebijakan yang meliputi:
a-1. Penyusunan kebijakan data, informasi, dan sistem kontrol kawasan lalu lintas,

a-2. Penyusunan kebijakan atas 
pemeliharaan sarana prasarana lalu lintas dan penerangan jalan umum, dan

a-3. Penyusunan kebijakan manajemen rekayasa lalu lintas dan jaringan transportasi.

b. Pelaksanaan kegiatan program, berisikan

kegiatan-kegiatan yang meliputi:

b-1. Pembuatan kartu pengawas/izin operasi,

b-2. Rekomendasi persetujuan peremajaan angkutan umum,

b-3. Pembuatan izin residentil,

b-4. Pemberian izin usaha angkutan,

b-5. Surat masuk, dan

b-6. Surat keluar.

c. Pelaksanaan evaluasi dan monitoring, dan

d. Pelaksanaan tugas lainnya yang diberikan oleh Kepala Dinas.

Proses bisnis ini secara umum melibatkan Kepala Dinas sebagai pengambil keputusan. Selanjutnya, pegawai yang termasuk dalam Bidang Lalu Lintas \& Jalan, Bidang Angkutan, Bidang Perairan \& Udara memiliki keterlibatan penuh terhadap kegiatan bisnis. Adapun fungsifungsi bisnis yang terdapat pada Dinas Perhubungan Kota Balikpapan ini dimodelkan dalam arsitektur bisnis menggunakan Archimate 3.0 yang dapat dilihat pada Gambar 2 berikut.

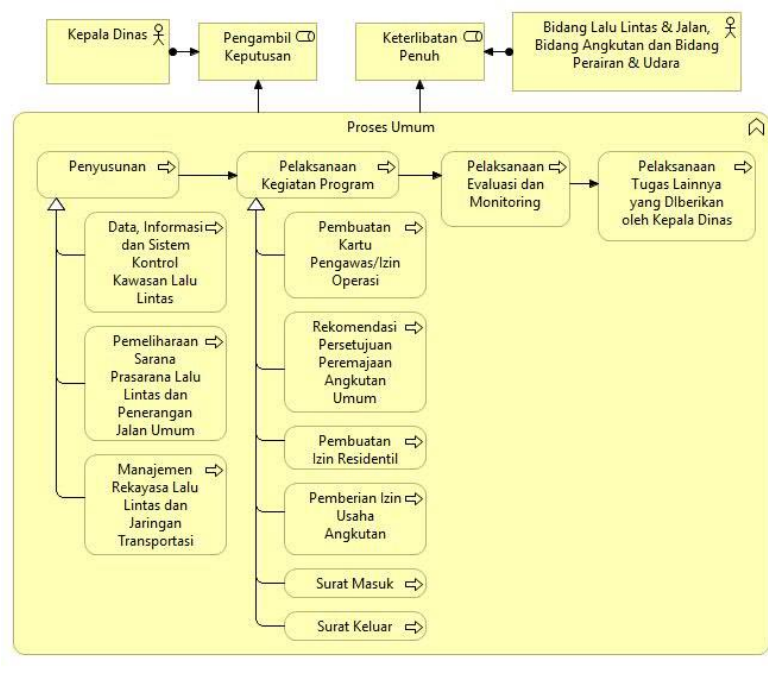

Gambar 2. Arsitektur Bisnis Dinas Perhubungan Kota Balikpapan

\section{Arsitektur Sistem Informasi}

a. Arsitektur Data

Arsitektur data mendefinisikan jenis entitas data yang digunakan oleh setiap proses bisnis. Sumber entitas data diperoleh dari kegiatan wawancara terhadap Dinas Perhubungan Kota Balikpapan. Hubungan antara proses bisnis dengan entitas datanya didetailkan pada Tabel 1 berikut.

Tabel 1. Identifikasi Data

\begin{tabular}{|c|c|}
\hline Proses Bisnis & Entitas Data \\
\hline \multirow{6}{*}{$\begin{array}{l}\text { Data, Infor } \\
\text { Sistem } \\
\text { Kawasan } \\
\text { Lintas }\end{array}$} & $\begin{array}{lrr}\begin{array}{l}\text { Data } \\
\text { (Area }\end{array} & \text { Traffic } & \text { ATCS } \\
\text { System) } & \text { Control } \\
\text { Srat }\end{array}$ \\
\hline & Data APILL (Alat \\
\hline & Pemberi Isyarat Lalu \\
\hline & \\
\hline & $\begin{array}{l}\text { Data Status Ruas dan } \\
\text { Jalan Kota Balikpapan }\end{array}$ \\
\hline & $\begin{array}{l}\text { Data Dasar Prasarana } \\
\text { Jalan Kota Balikpapan }\end{array}$ \\
\hline \multirow{4}{*}{$\begin{array}{l}\text { Pemeliharaan } \\
\text { Sarana Prasarana } \\
\text { Lalu Lintas dan } \\
\text { Penerangan Jalan } \\
\text { Umum }\end{array}$} & $\begin{array}{l}\text { Data Status Ruas dan } \\
\text { Jalan Kota Balikpapan }\end{array}$ \\
\hline & Data Zebra Cross \\
\hline & $\begin{array}{l}\text { Data PJU (Penerangan } \\
\text { Jalan Umum) }\end{array}$ \\
\hline & $\begin{array}{l}\text { Data Rambu-Rambu } \\
\text { Jalan }\end{array}$ \\
\hline $\begin{array}{l}\text { Administrasi } \\
\text { Umum }\end{array}$ & $\begin{array}{l}\text { Surat Masuk, } \\
\text { Keluar }\end{array}$ \\
\hline \multirow{2}{*}{$\begin{array}{l}\text { Manajemen } \\
\text { Rekayasa Lalu } \\
\text { Lintas dan Jaringan } \\
\text { Transportasi }\end{array}$} & $\begin{array}{ll}\text { Data } & \text { Kendaraan } \\
\text { Bermotor } & \\
\end{array}$ \\
\hline & $\begin{array}{ll}\text { Data } & \text { ANDALALIN } \\
\text { (Analisis } & \text { Dampak Lalu } \\
\text { Lintas) } & \end{array}$ \\
\hline \multirow{4}{*}{ Bidang Angkutan } & $\begin{array}{l}\text { Data Kartu Pengawasan } \\
\text { Ijin Trayek }\end{array}$ \\
\hline & $\begin{array}{l}\text { Data Kartu Pengawasan } \\
\text { Ijin Operasi }\end{array}$ \\
\hline & Data Angkutan Umum \\
\hline & Data Izin Residentil \\
\hline
\end{tabular}

b. Arsitektur Aplikasi

Pada dasarnya, arsitektur aplikasi bertujuan mendefinisikan jenis sistem informasi yang dibutuhkan untuk mengelola data dan menyediakan informasi untuk mendukung organisasi dalam melaksanakan proses bisnisnya. Pada Tabel 2 dideskripsikan beberapa jenis sistem informasi yang diimplementasikan oleh Dinas Perhubungan Kota Balikpapan, antara lain sebagai berikut: 
Tabel 2. Sistem Informasi Saat Ini

\begin{tabular}{|c|c|c|}
\hline Sistem Informasi & Deskripsi & Entitas Data \\
\hline $\begin{array}{l}\text { Website Dinas } \\
\text { Perhubungan }\end{array}$ & 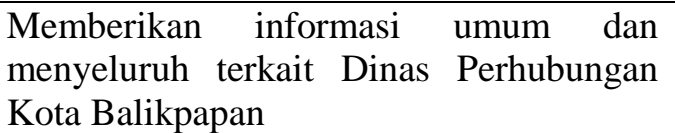 & $\begin{array}{l}\text { Informasi dan Dokumentasi } \\
\text { hasil kegiatan pelayanan }\end{array}$ \\
\hline $\begin{array}{l}\text { TMC (Traffic } \\
\text { Management Center) } \\
\text { Kota Balikpapan }\end{array}$ & $\begin{array}{l}\text { Aplikasi pemantau arus lalu lintas Kota } \\
\text { Balikpapan secara real time, selain itu } \\
\text { aplikasi ini terintegrasi dengan beberapa } \\
\text { aplikasi lain yang dikelola Dinas } \\
\text { Perhubungan Kota Balikpapan. }\end{array}$ & $\begin{array}{l}\text { a. Data CCTV ATCS (Area } \\
\text { Traffic Control System), } \\
\text { b. Data APILL (Alat Pemberi } \\
\text { Isyarat Lalu Lintas), } \\
\text { c. Data Status Ruas dan Jalan } \\
\text { Kota Balikpapan, } \\
\text { d. Data Dasar Prasarana Jalan } \\
\text { Kota Balikpapan } \\
\end{array}$ \\
\hline $\begin{array}{l}\text { MATA PERHU- } \\
\text { BUNGAN } \\
\text { (Manajemen Data } \\
\text { ANDALALIN } \\
\text { Dinas } \\
\text { Perhubungan } \\
\text { Kota Balikpapan) } \\
\end{array}$ & $\begin{array}{l}\text { Aplikasi yang mengintegrasikan data, } \\
\text { informasi dan rekomendasi atas hasil } \\
\text { Analisa Dampak Lalu Lintas } \\
\text { (ANDALALIN) suatu pembangunan fisik } \\
\text { baik yang bersifat komersil/non komersil } \\
\text { berbasis spasial dan real time yang dapat } \\
\text { diakses melalui smartphone. }\end{array}$ & $\begin{array}{l}\text { ALIN (Analisis } \\
\text { Lintas) }\end{array}$ \\
\hline $\begin{array}{l}\text { SIM-PKB (Sistem } \\
\text { Informasi Manajemen } \\
\text { Pengujian Kendaraan } \\
\text { Bermotor) }\end{array}$ & $\begin{array}{l}\text { Aplikasi manajemen sistem pelayanan } \\
\text { pengujian kendaraan bermotor sekaligus } \\
\text { pengawasan kendaraan bermotor wajib } \\
\text { uji. }\end{array}$ & Data Kendara \\
\hline $\begin{array}{l}\text { SIMAU (Sistem } \\
\text { Informasi Manajemen } \\
\text { Angkutan Umum) }\end{array}$ & $\begin{array}{l}\text { Aplikasi yang berfungsi rebagai } \\
\text { manajemen sistem pelayanan Kartu } \\
\text { Pengawasan Ijin Trayek, Kartu Pengawas- } \\
\text { an Ijin Operasi serta Peng-awasan } \\
\text { Angkutan Umum. }\end{array}$ & $\begin{array}{l}\text { a. Data Kartu Pengawasan Ijin } \\
\text { Trayek, } \\
\text { b. Data Kartu Pengawasan Ijin } \\
\text { Operasi, } \\
\text { c. Data Angkutan Umum } \\
\end{array}$ \\
\hline
\end{tabular}
menggambarkan entitas data yang digunakan

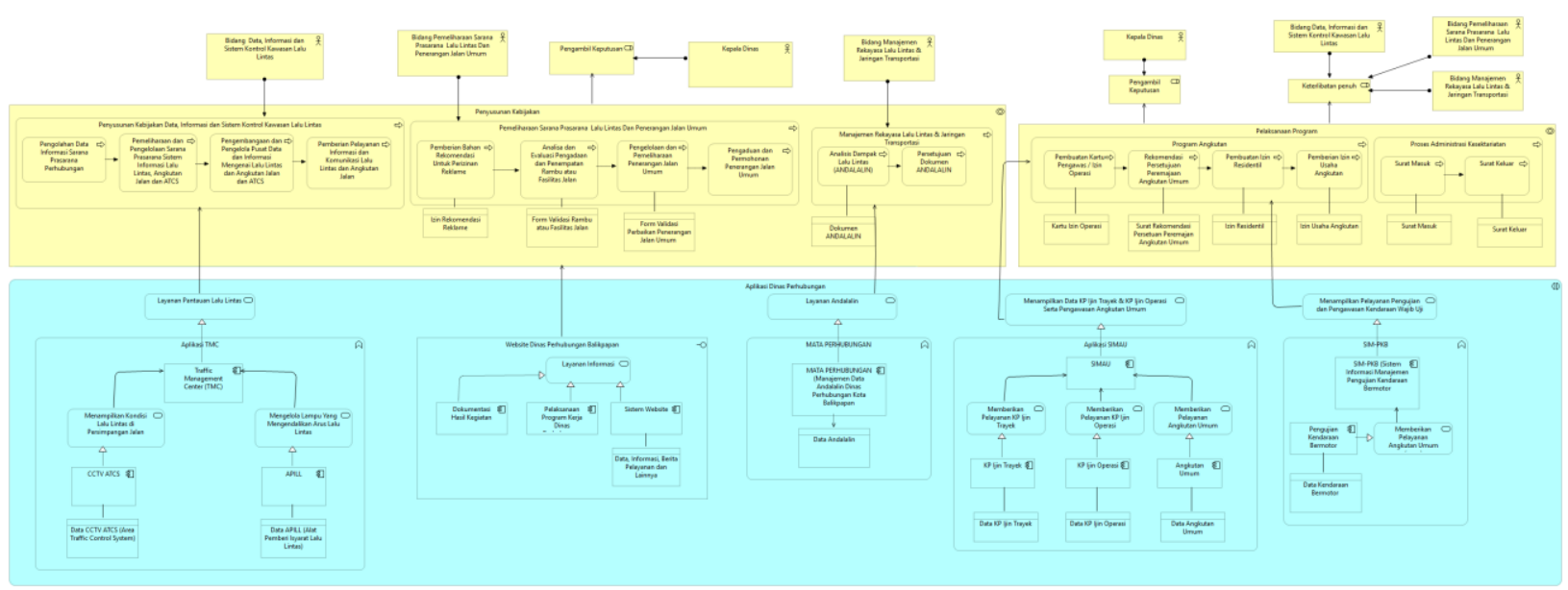

Gambar 3. Arsitektur Sistem Informasi Dinas Perhubungan Kota Balikpapan

\section{Arsitektur Teknologi}

Arsitektur teknologi mendeskripsikan infrastruktur teknologi yang terdiri dari perangkat lunak (software), perangkat keras (hardware), dan jaringan (network) yang berperan dalam menjalankan aplikasi dan data 
yang mendukung kebutuhan bisnis Dinas Perhubungan Kota Balikpapan.

a. Konfigurasi Perangkat Keras

Dinas Perhubungan Kota Balikpapan menggunakan beberapa perangkat keras dalam mengoperasikan sistem informasi yang ada ditunjukkan pada Tabel 3 sebagai berikut:

Tabel 3. Konfigurasi Hardware

\begin{tabular}{ll}
\hline Hardware & \multicolumn{1}{c}{ Spesifikasi } \\
\hline Server & DELL R710 SIX CORE XEON \\
& X5690 3.4GHZ DOBEL \\
& Processor RAM 16GB HDD \\
& 300gb SAS X \\
\hline Laptop & ASUS X441SA-BX001D \\
\hline PC & Asus I5 2400 4Gb 320Gb KM \\
& 19 Inch Futur \\
\hline Router & Mikrotik CCR1009-7G-1C-PC \\
& Routerboard Cloud Core Router \\
\hline Access & MikroTIK Metal 2SHPn 1 \\
Point & Metal2 SHPn 1 Metal 2 SHPn \\
& (Access Point 2GHz) \\
\hline Printer & HP Printer Laserjet M102A A4 \\
\hline Switch & PLANET GS-4210-24T2S 24- \\
& Port Layer 2 Managed Gigabit \\
& Ethernet Switch \\
\hline
\end{tabular}

b. Konfigurasi Perangkat Lunak
Pada Tabel 4 mendeskripsikan perangkat lunak yang digunakan dalam mendukung infrastruktur sistem informasi pada Dinas Perhubungan Kota Balikpapan.

Tabel 4. Konfigurasi Software

\begin{tabular}{ll}
\hline \multicolumn{1}{c}{ Software } & \multicolumn{1}{c}{ Spesifikasi } \\
\hline Server & Centos 7 \\
\hline Web Server & Apache \\
\hline DBMS & My SQL \\
& PostgreSQL \\
& Shp \\
\hline $\begin{array}{l}\text { Operating } \\
\text { System }\end{array}$ & Windows 10 \\
\hline
\end{tabular}

c. Konfigurasi Jaringan

Dinas Perhubungan Kota Balikpapan mengimplementasi desain tree atau pohon pada topologi jaringan yang digunakan pada infrastruktur Dinas Perhubungan Kota Balikpapan. Arsitektur teknologi yang dimodelkan menggambarkan sistem dan peralatan yang diperlukan untuk menjalankan aplikasi dan memproses data pada gedung Dinas Perhubungan Kota Balikpapan yang terdiri dari 4 lantai. Sehingga, arsitektur teknologi yang diimplementasi digambarkan seperti pada Gambar $\quad 4 \quad$ berikut:

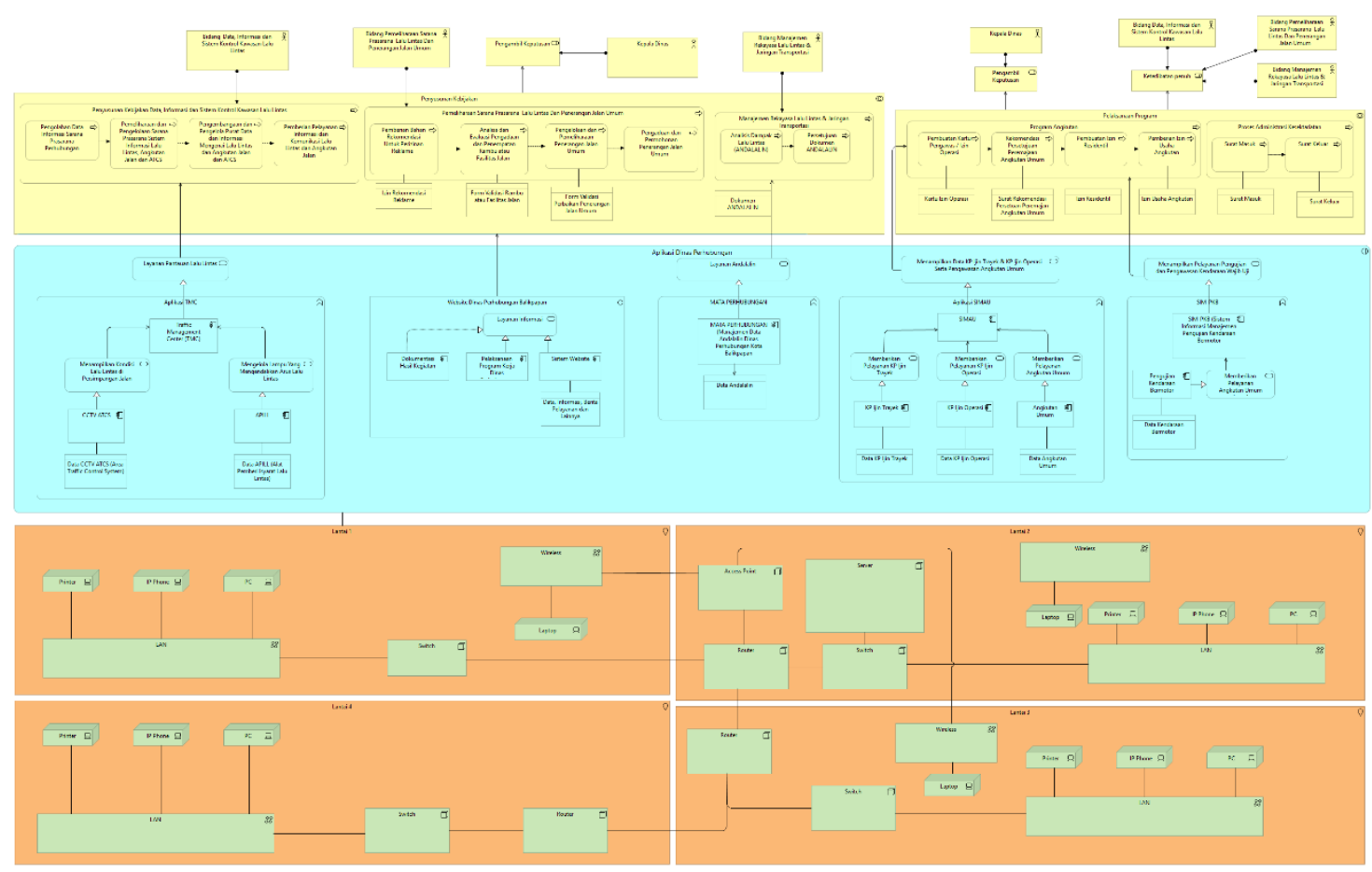

Gambar 4. Arsitektur Teknologi Dinas Perhubungan Kota Balikpapan 


\section{Opportunities \& Solution}

Dilakukan identifikasi proses bisnis yang memerlukan dukungan sistem informasi berdasarkan penilaian faktor bisnis yang mungkin akan berpengaruh terhadap proses bisnis organisasi. Terdapat 4 faktor bisnis krusial yang perlu dipertimbangkan dalam membuat proritas pengembangan [15] yaitu:

1. Demand, yaitu derajat kebutuhan organisasi terhadap sistem informasi

2. Risk, yaitu peluang untuk mencapai kesuksesan. Hal yang harus diperhatikan meliputi perhitungan kebutuhan dan ketersediaan sumber daya.

3. Potential benefit, yaitu pemberian prioritas terhadap sistem informasi yang memiliki tingkat Return on Investment (ROI) yang tinggi.

4. Organizational Impact, yaitu prioritas terhadap sistem informasi yang tidak berdampak ekstrim terhadap organisasi.

Penilaian terhadap sistem informasi dilakukan untuk setiap faktor bisnis dan kemudian dihitung nilai akumulasinya. Skor diberikan dalam rentang 1-4. Sistem informasi dengan nilai lebih besar akan mendapat prioritas lebih tinggi dibanding sistem informasi lainnya. Pemberian nilai dilakukan dengan pertimbangan terhadap sistem informasi yang bersifat kepentingan proses binsis. Hasil identifikasi terhadap kebutuhan bisnis dapat dilihat pada Tabel 5 . Sebagai hasil akumulasi, diperoleh aplikasi dengan prioritas pengembangan tertinggi merupakan aplikasi TMC Kota Balikpapan.

Tabel 5 Prioritas Pengembangan Aplikasi

\begin{tabular}{|c|c|c|c|c|c|}
\hline Sistem Informasi & 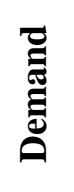 & $\frac{1}{4}$ & 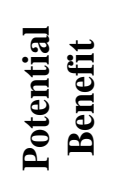 & 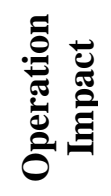 & \\
\hline $\begin{array}{l}\text { TMC (Traffic } \\
\text { Management } \\
\text { Center) }\end{array}$ & 4 & 2 & 4 & 4 & \\
\hline $\begin{array}{l}\text { SIM-PKB (Sistem } \\
\text { Informasi } \\
\text { Manajemen } \\
\text { Pengujian } \\
\text { Kendaraan } \\
\text { Bermotor) }\end{array}$ & 4 & 2 & 3 & 4 & \\
\hline $\begin{array}{l}\text { SI-MAU (Sistem } \\
\text { Informasi } \\
\text { Manajemen }\end{array}$ & 4 & 2 & 3 & 4 & \\
\hline
\end{tabular}

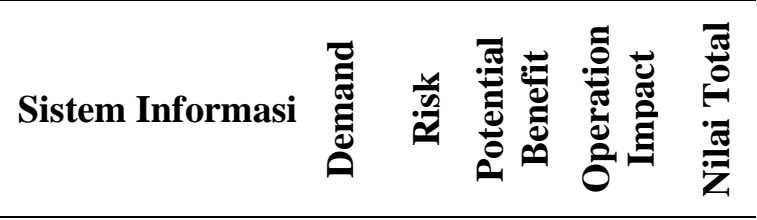

Angkutan Umum)

MATA

PERHUBUNGA

$\mathrm{N}$ (Manajemen

Data

ANDALALIN

$\begin{array}{llll}4 & 2 & 2 & 3\end{array}$

11

Dinas

Perhubungan

Kota Balikpapan)

Website Dinas

Perhubungan

$\begin{array}{llll}3 & 2 & 2 & 3\end{array}$

10

\section{SIMPULAN DAN SARAN}

Dari penelitian yang telah dilakukan dapat diambil kesimpulan bahwa penelitian berhasil memetakan kebutuhan bisnis Dinas Perhubungan Kota Balikpapan dan kebutuhan aplikasi untuk mendukung visi dan misi yang ingin dicapai melalui rancangan arsitektur SI/TI meliputi pemodelan arsitektur bisnis, arsitektur sistem informasi, dan arsitektur teknologi menggunakan kerangka kerja TOGAF ADM. Secara keseluruhan, sejumlah 5 (lima) aplikasi saat ini perlu untuk dipertahankan dan terus dikembangkan untuk dapat mendukung dan selaras terhadap kebutuhan dan tujuan Dinas Perhubungan Kota Balikpapan.

Berdasarkan hasil penelitian yang sudah diperoleh, terdapat beberapa saran agar penelitian ini menjadi lebih baik dimasa yang akan datang, antara lain:

1. Tahapan pada TOGAF ADM perlu dilanjutkan sampai tahap migration planning, tata kelola teknologi informasi, dan fase manajemen perubahan agar pengimplementasian aristektur SI/TI dapat menjadi lebih mudah dengan melakukan iterasi kembali untuk penyempurnaan.

2. Diharapkan pada penelitian selanjutnya agar dapat mengembangkan penggunaan tools yang lebih baik agar rancangan arsitektur yang dihasilkan juga dapat mengikuti perkembangan teknologi di kemudian hari. 
3. Perancangan arsitektur SI/TI yang dilakukan untuk perkembangan proses bisnis harus mendapatkan dukungan dan komitmen yang maksimal dari semua stakeholder.

\section{UCAPAN TERIMA KASIH}

Penulis mengucapkan terimakasih kepada Kementrian Riset, Teknologi, dan Pendidikan Tinggi atas bantuan biaya dari Penelitian Dosen Pemula Kementrian Riset, Teknologi, dan Pendidikan Tinggi tahun 2019 sehingga terselesaikannya penelitian perancangan arsitektur sistem informasi dan teknologi informasi pada Dinas Perhubungan Kota Balikpapan. Selanjutnya, penulis juga mengucapkan terimakasih kepada Dinas Perhubungan Kota Balikpapan yang telah terlibat dan bekerja sama selama penelitian berlangsung.

\section{REFERENSI}

[1] B. Subaeki, "Perancangan Arsitektur Sistem Informasi Menggunakan Metode Enterprise Arsitektur Planning," J. Tata Kelola dan Kerangka Kerja Teknol. Inf., vol. 2, no. 3, pp. 1-18, 2017.

[2] Suhendri, "Pemodelan Arsitektur Enterprise Menggunakan Framework Gartner ( Studi Kasus: IAIN Syekh Nurjati Cirebon )," Infotech J., vol. 1, pp. 16-20, 2015.

[3] I. Safarina, I. K. Raharjana, and E. Purwanti, "Perencanaan Arsitektur Perusahaan untuk Pengelolaan Aset di PT. Musdalifah Group menggunakan Kerangka Kerja Zachman," J. Inf. Syst. Eng. Bus. Intell., 2015.

[4] A. W. Sudrajat, "Penerapan Framework Zachman Dalam Perancangan Arsitektur Sistem Manajemen Penyusunan Anggaran Keuangan Daerah (Studi Kasus UPTD Graha Teknologi Sriwijaya)," Creat. Inf. Technol. J., 2015.

[5] R. Irfanto and J. F. Andry, "Perancangan Enterprise Architecture Menggunakan Zachman Framework (PT. Vivamas Adipratama)," Semnastek UMJ, 2017.

[6] B. R. Fadilah, R. Andreswari, R. Hanafi, P. Studi, S. Informasi, and F. R. Industri,
"Integrasi Modul Sumber Daya Manusia dan Pengadaan dengan Pendekatan Enterprise Architecture untuk Meningkatkan Efisiensi Waktu Pelaksanaan Proses Bisnis Integrated Human Resource and Procurement Module with Enterprise Architecture Approach to Improve Effi," vol. 05, no. 02, 2018.

[7] H. Husain, P. N. Andono, and M. A. Soeleman, "Perspektif Baru Enterprise Architecture Pemerintahan Kota Mataram Berbasis TOGAF ADM," $J$. Matrik, 2017.

[8] D. Rahmayanti, R. Andreswari, and R. Hanafi, "Analisis Dan Perancangan Enterprise Architecture Direktorat Metrologi Pada Fungsi Kepegawaian Dan Keuangan Menggunakan Framework Togaf ADM," J. Rekayasa Sist. Ind., 2017.

[9] H. Widiyanto, R. Abidirin, and L. Emha, "Analisis Pemodelan Arsitektur Enterprise Untuk Mendukung Sistem Informasi Akademik Dengan Togaf (The Open Group Architecture framework) (Studi Kasus AMIK AMIKOM Surakarta)," J. Duta, 2013.

[10] Gartner, "Gartner Clarifies the Definition of the Term ' Enterprise Architecture '," Gartner, 2008.

[11] The Open Group, TOGAF Version 9.1 Enterprise Edition. 2011.

[12] H. N. Syaddad, "Perancangan Model Arsitektur Sistem Informasi Di Perguruan Tinggi Menggunakan Togaf Architecture Development Methode ( Studi Kasus: Universitas Suryakancana )," Media J. Inform., vol. 7, no. 2, pp. 927, 2015.

[13] R. Setiawan, "Perancangan Arsitektur Enterprise Untuk Perguruan Tinggi Swasta Menggunakan TOGAF ADM," $J$. Algoritm. STT Garut, 2015.

[14] N. G. Ayu Dasriani and R. Rismayati, "Architecture Enterprise Program Studi S1 Teknik Informatika dengan TOGAF Architecture Development Method (Studi Kasus: STMIK Bumigora Mataram)," MATRIK J. Manajemen, Tek. Inform. 
dan Rekayasa Komput., 2018.

[15] W. A. Arifiyanto and K. Surendro, "Enterprise architecture for egovernment in indonesia," in
Proceedings of the 2009 International Conference on Electrical Engineering and Informatics, ICEEI 2009, 2009. 